\title{
The Wistar Institute Cancer Center
}

National Cancer Institute

\section{Source}

National Cancer Institute. The Wistar Institute Cancer Center. NCI Thesaurus. Code C39535.

The Wistar Institute Cancer Center is committed to conducting basic research to benefit society and to training the next generation of scientists. The Center's scientists pursue research in three programs Gene Expression and Regulation, Molecular and Cellular Oncogenesis, and T umor Microenvironment and Metastasis. It was named an $\mathrm{NCl}$ designated cancer center in basic research in 1972. 